\title{
New Cultivars
}

Keywords: cultivar, D ionaea muscipula 'Sensor', C ephalotus 'Elizabeth', Sarracenia 'Ellie Wang', Sarracenia 'Flavona'.

\section{Dionaea muscipula 'Sensor'}

Submitted: 1 M ay 2018

In September 2013, I first noticed that this plant had unique characteristics compared to other Dionaea muscipula: the teeth of the traps merged in variable groups (Fig la) and there were always six to nine sensory trigger hairs within the trap on each side (Fig $1 \mathrm{~b}$ ). This characteristic has been persistent and is more accentuated during the spring/summer vegetative period. Each trigger hair proved to be functional and useful for closing the trap.

Dionaea 'Sensor' differs from Dionaea 'Carniplant' in that Dionaea 'Sensor' never is bright red and usually attains only a peach color, the teeth remain almost white, and it maintains 12 to 15 trigger hairs per trap.

Growth has always been particularly vigorous, producing many leaves and new rhizome divisions each year. The plant remains mostly prostrate and reaches a good diameter. The color inside traps is sometimes remains green despite bright sunlight. These characteristics have been stable and persistent since 2013.

The perfect name that immediately came to mind on 24 A ugust 2014 for this cultivar was "Sensor", because of the high number of trigger hairs and for the sensory capacity that each trigger hair has to close the trap.

Dionaea muscipula 'Sensor' must be reproduced vegetatively to preserve the characteristics of the cultivar.

Stefano Lascialfari • Via delle Cento Stelle 13 • 50137 Firenze • Italy • steno79@inwind.it
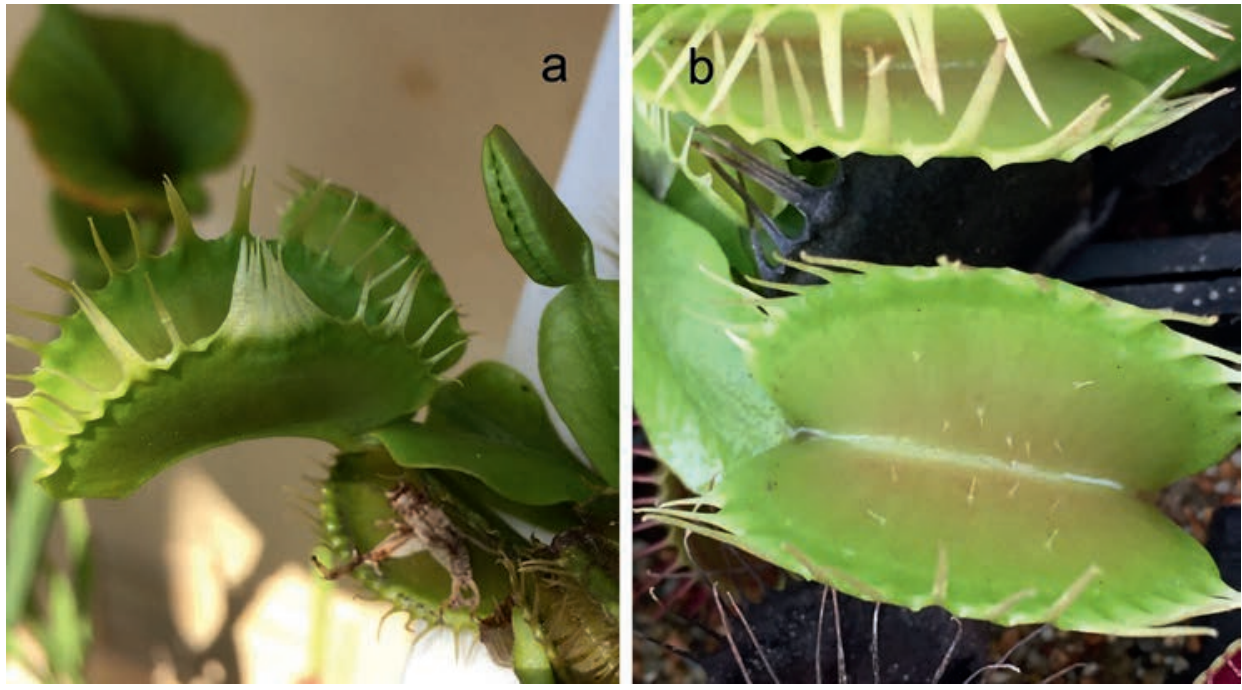

Figure 1: Dionaea muscipula 'Sensor' merged teeth (a) and numerous white trigger hairs (b). 
Submitted: 31 M ay 2018

Cephalotus 'Elizabeth' has absolutely been a true joy for me to grow since I received it in December of 2011. It was originally selected for its overly defined peristome, as well as for being rather hairy. However, after sharing the plant with other carnivorous plant hobbyists here in O regon, an even more captivating feature was brought to my attention. Instead of having the normal lid of a typical Cephalotus pitcher which curves downward towards the peristome, the lid of C. 'Elizabeth' stands completely upright (Fig. 2). In doing so, the lid flattens out and slightly splits to a notch in the middle to accommodate for the stretch. The average adult pitcher size is about $5 \mathrm{~cm}$ excluding the added height of the lid. Including the lid, adult pitchers reach $7 \mathrm{~cm}$. In strong lighting, C. 'Elizabeth' produces alluring, dark pitchers. It does not produce many non-carnivorous leaves in my experience, however C. 'Elizabeth' is propagated just as easily by pitcher pullings.

A fter many years of quietly propagating $C$. 'Elizabeth', I've come to appreciate the unique characteristics it holds true to and am very excited to finally share it with the community. It regularly commands a closer look from hobbyists and new comers alike. For me, C. 'Elizabeth' happily grows under a set of $\mathrm{T} 5 \mathrm{HO}$ lights $12-15$ hours a day with an average temperature of between $21-24^{\circ} \mathrm{C}$. Reproduction of C. 'Elizabeth' must be vegetative to maintain its specific traits.

-Christina ToOle • P.O. Box 1227 • Oregon City • Oregon 97045 • USA • christina61086@ yahoo.com
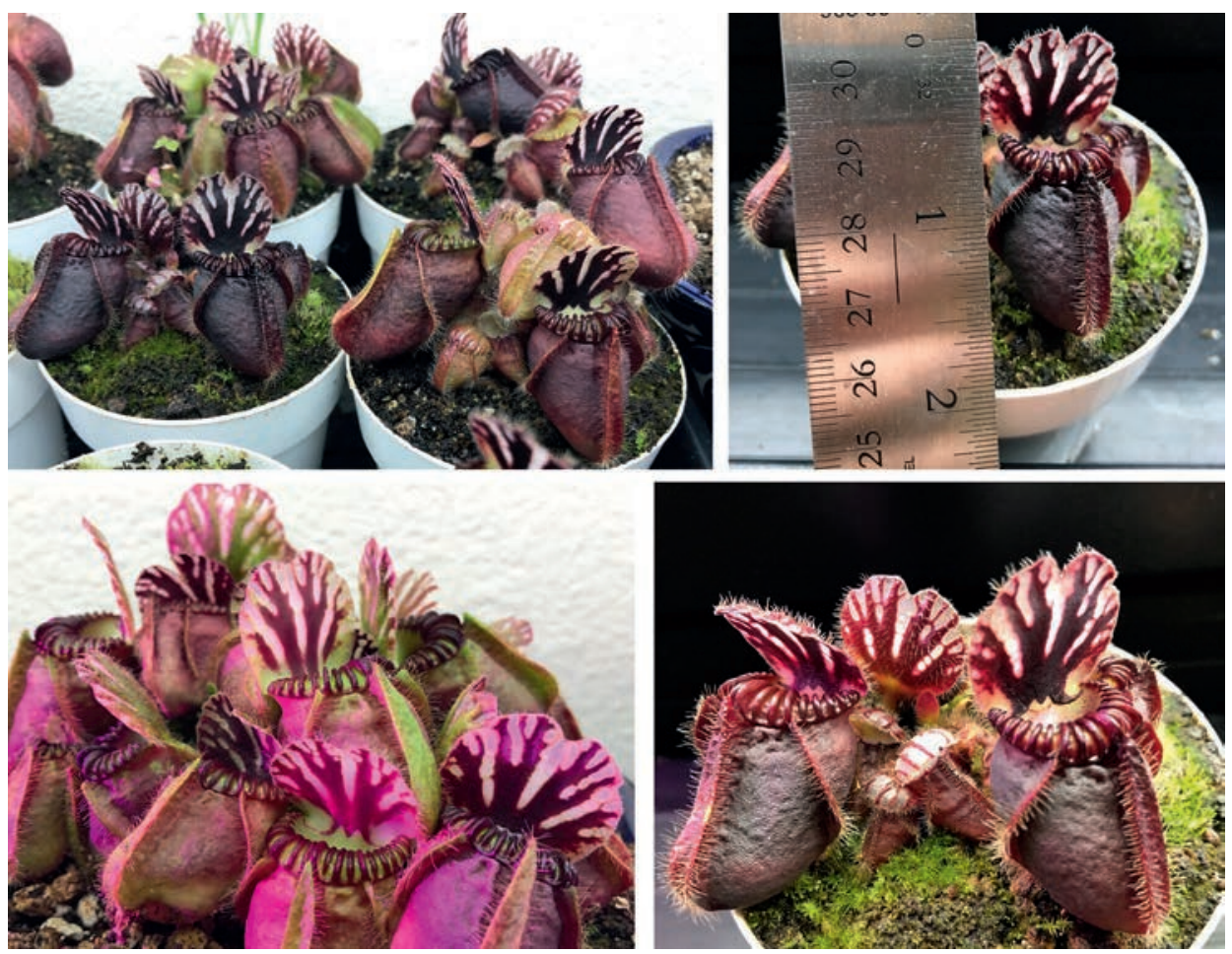

Figure 2: Cephalotus 'Elizabeth'. 
Sarracenia 'Ellie Wang' is a very complex man-made hybrid, the details of the cross remain a trade secret. This spectacular and stand out bi-colored individual has a bright white lid with a solid, bright raspberry-red body (Fig. 3). The sharp contrast between the two colors make this plant stick out of the crowd! The top of the lid contains a network of stunning red veins. The entire interior of the oval-shaped mouth, including the neck of the trap, has subtle dark veins with a solid raspberryred background. The neck of the trap, relative to the mouth and lid, is somewhat thin. Outdoors in Northern California, the plant consistently colors up very easily and does not require an "artificial suntan" or greenhouse cultivation to reach its fullest color potential.

One great feature of this cultivar is the growth habit: under optimal conditions, each growth point can produce multiple pitchers throughout the grow season. The traps color up immediately upon opening, but reach their peak, deepest color potential about 2 weeks after opening. Sarracenia 'Ellie Wang' is a vigorous and easy to grow cultivar.

Under my conditions, the traps have reached a maximum of $61 \mathrm{~cm}$ in height in a $15.24 \mathrm{~cm}$ pot, although I suspect this cultivar may be able to produce slightly taller pitchers if given a bigger pot.

The flowers have red petals, red sepals, and red tepals. Overall, it's nearly indistinguishable from a typical Sarracenia leucophylla flower.

Sarracenia 'Ellie Wang' must be produced by vegetative means to maintain the unique color features and growth habit.

This cultivar is named after my daughter, Ellie Wang, who is named after Eleanor Roosevelt. During World War II, Eleanor Roosevelt sent ships overseas to help save people fleeing from the Nazi invasion, which saved the lives of my Russian grandparents and gave them an opportunity to relocate to São Paulo, B razil. Had she not sent those ships, I would not likely be writing this cultivar description today!

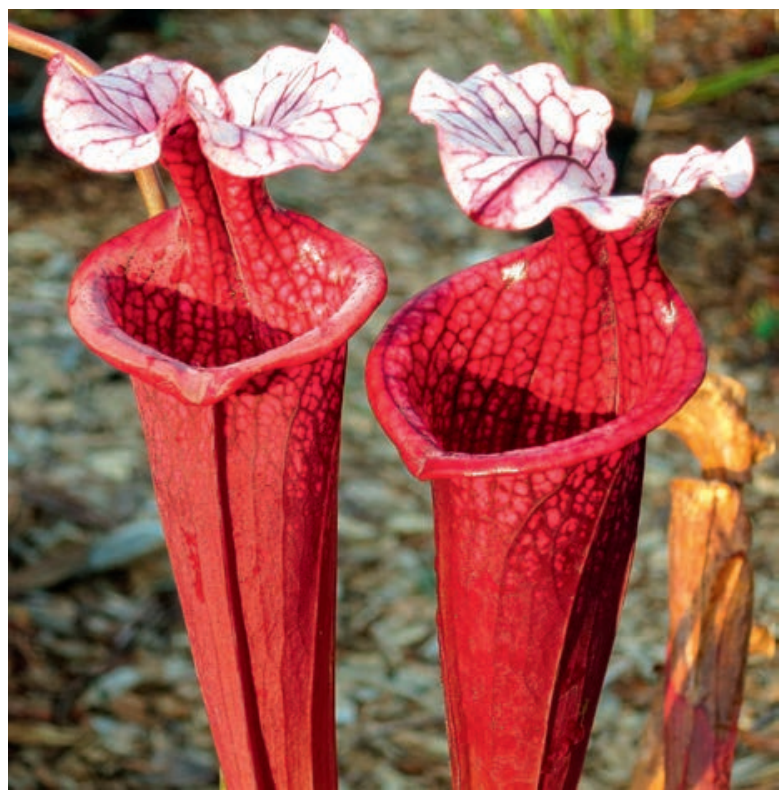

Figure 3: Sarracenia 'Ellie Wang'.

—MIKE WANG • San Francisco Bay Area • California • USA • meizzwang@gmail.com 
I have been cultivating this Sarracenia since August 1996, after receiving a small division of rhizome from a gardener of the B otanical Garden of Geneva (Switzerland), as a gift. I was visiting the garden when I was amazed at the greatness of that plant growing in a greenhouse. $A$ kind and generous curator, seeing me so fascinated and impressed, he detached a piece of the great rhizome and gave it to me.

So, I have the pleasure and the honor of cultivating this specimen for 22 years, I grew it with great success and the plant has always been very vigorous in its devel opment. I have divided it many times and it is widely spread among the various growers and enthusiasts in I taly and Europe.

The plant is also informally named as "F199 Mike King", my friend and sublime English grower, known all over the world. M ike received a division from me in 2004.

Its morphological and chromatic characteristics are typical of the species Sarracenia flava, probably a hybrid between S. flava var. ornata and S. flava var. rugelii, or a back-cross, but I cannot tell if it is natural or man-made because I do not know its story before 1996.

The major traps grow between the end of $\mathrm{M}$ arch and mid-M ay, just after the buds have sprouted. The typical "phyllodia" grow during the warmer season. Towards the middle and the end of the summer new traps develop, smaller than in spring and with more veins on the neck and under the lid.

The throat is strongly stained red, while under the lid dark red veins are drawn that appear more finely also on the body of the pitcher tube, more towards the top, light green in spring to become pale yellow in full summer, under strong light conditions (Fig. 4). The flowers are typical of the species Sarracenia flava, yellow, with stems between 60 and $70 \mathrm{~cm}$ high.
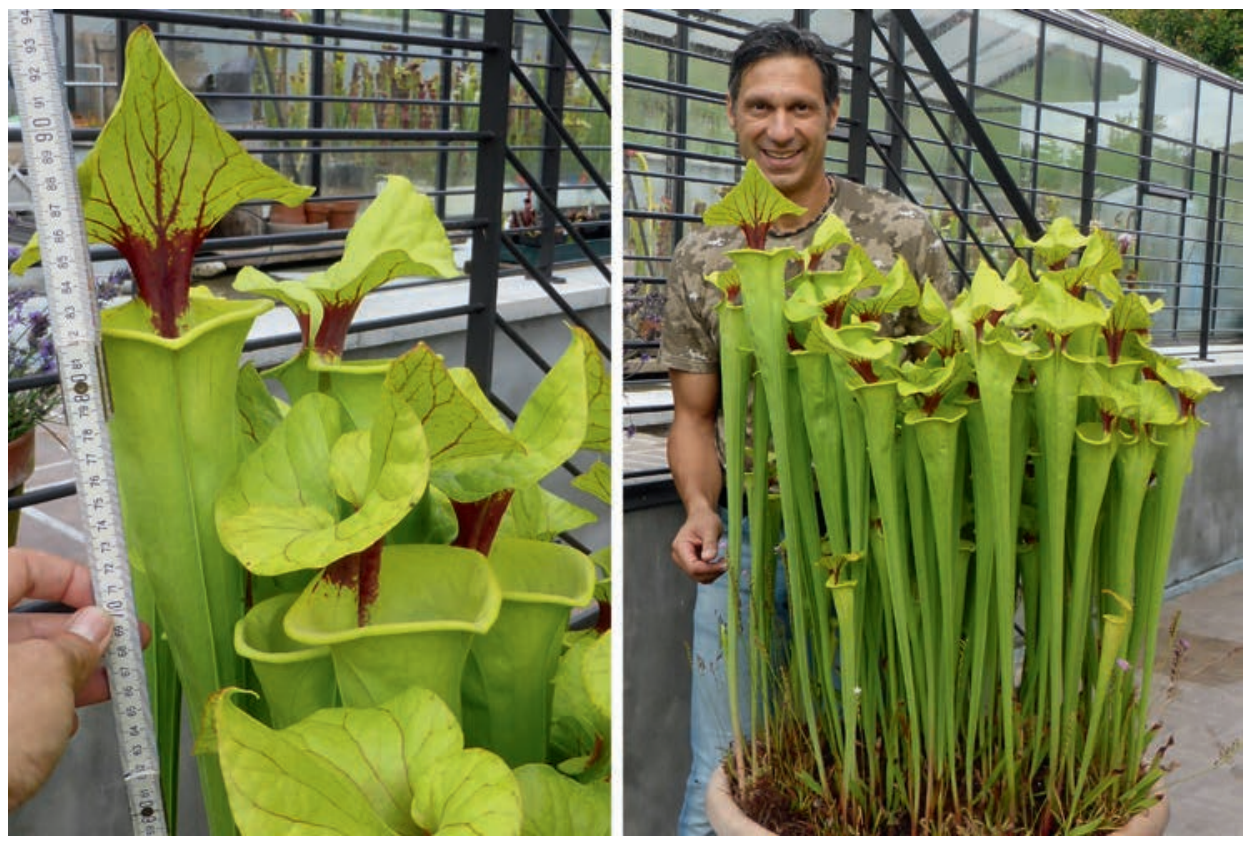

Figure 4: A 93-cm tall Sarracenia 'Flavona' pitcher (left) and over 50 pitchers growing in an 80-cm diameter bowl (right). 
For three years, I have been cultivating it in a round bowl, $25 \mathrm{~cm}$ deep and with a diameter of $80 \mathrm{~cm}$, which now completely fills with a single, individual rhizome that has many and indefinable growth points.

It has always had, over the years with me, an imposing size, with average heights of the larger pitchers between 70 and $80 \mathrm{~cm}$, with peristome diameters between 9 and $12 \mathrm{~cm}$. Remarkable!

This year, however, it is truly impressive: its overall size and proportions are beyond expectations and every other vintage!

Here's the surprise: in the spring of 2018, the plant developed 50 to 60 pitchers, many of which are over $80 \mathrm{~cm}$ tall, the highest developed up to $92-93 \mathrm{~cm}$ (Fig. 4) and 11-12 cm wide!! Incredible and wonderful! Powerful! A colossus!

The pitcher lids, measured from above, reach up to $14-15 \mathrm{~cm}$ in diameter! Almost as wide as an open hand. I understood from the first sprouts in A pril that they would be big traps, as the bases of some are almost $1 \mathrm{~cm}$. A pure show!

This fantastic and perfect proportion between the width of the entrance and the height of the whole trap is the real secret of the fatal attraction of this specimen, a true plant monster, a vegetable giant of great magnetism and charm.

Personally, despite 35 years of cultivation, having seen and cultivated many Sarracenia and visited various collections, I cannot remember a plant so capable of striking at the heart of every fan of the genus every time he/she manages to meet closely. For this reason, I decided to officially register it, in order to pay homage and name this unique cultivar of Sarracenia flava.

I repeat, growing it in my greenhouse for 22 years is a pleasure and an honor for me, still grateful to the B otanical Garden of Geneva for the gift of many years ago and also grateful to S. 'Flavona' for the amazement it was able to give me in these years.

Naturally, the epithet "Flavona" is the Italian superlative of "flava", in order to describe the gigantism of its proportions in one word.

To be sure of keeping the characteristics unaltered, multiplication is carried out by division of the rhizome.

—ANDREA AMICI • via dei Ciclamini, 47 • 40043, Marzabotto • Bologna • Italia • cephalotus@ libero.it $\bullet$ http://www.phylla.com/ilpigliamosche 